\title{
PRÁTICAS INOVADORAS NA EDUCAÇÃO FÍSICA E A INCLUSÃO DO ALUNO TRABALHADOR
}

\author{
Wellington Correia Figueiredo, Celso Ricardo Marques, José Ricardo Silva \\ Faculdade de Presidente Prudente - FAPEPE. Presidente Prudente - SP. E-mail: pitico black1@hotmail.com
}

\begin{abstract}
RESUMO
Historicamente, a educação física escolar foi, por vezes, marcada por professores denominados rola bola cujas práticas relacionam-se à falta de planejamento e intervenção pedagógica levando a perda de interesse dos alunos em participar das aulas, sobretudo, os alunos trabalhadores. Por isso, o presente artigo tem como objetivo discorrer sobre nossas aulas educação física na Educação Básica e algumas experiênciasatuais e inovadoras que tornaram as aulas prazerosas einclusivas levando os alunos a um relaxamento psicológico e muscular em relação às atividades diárias. A metodologia utilizada foi a pesquisa bibliográfica. Concluímos que a educação física ainda está em processo de evolução. Segundo os autores citados as aulas não podem abordar somente os esportes, precisam ser planejadas e inovadoras para que haja interesse e a participação de todos os alunos inclusive, o aluno que trabalha.

Palavras-chave: Educação física, Rola bola, aluno trabalhador, inovação pedagógica, inclusão.
\end{abstract}

\section{INNOVATIVE PRACTICES IN PHYSICAL EDUCATION AND THE INCLUSION OF STUDENT WORKER}

\begin{abstract}
Historically, physical education was sometimes marked by teachers called rolling ball whose practices are related to the lack of planning and pedagogical intervention leading to loss of student interest in participating in class, especially working students. Therefore, this article aims to discuss our physical education classes in basic education and some current and innovative experiences that made the pleasurable and inclusive classes leading students to a psychological relaxation and muscle in relation to daily activities. The methodology used was the literature research. We conclude that physical education is still in process of evolution, second the authors mentioned classes can not address only the sports, need to be planned and innovative so that there is interest and participation of all students including the student who works.
\end{abstract}

Keywords: Physical education, Rolling ball, student worker, pedagogical innovation, inclusion.

\section{INTRODUÇÃO}

Ao relembrarmos de nossas aulas de educação física escolar, cursada no ensino público estadual, resgatamos aquelas experiências que nos possibilita atualmente, fazer algumas reflexões.

De modo geral, houve a presença do professor de Educação Física, mas em sua ausência, o professor substituto era o generalista ou de outra disciplina qualquer.Já no ensino fundamental e ensino médio, a maior lembrança do trabalho do professor eram aulas focadas na prática dos 
seguintes esportes: handebol, basquete, futsal, e voleibol. Durante estas práticas desportivas o professor explicava regras e fundamentos básicos do referido esporte. As aulas eram, em sua maioria, na quadra de caráter prático onde, após as informações básicas sobre os esportes, os alunos jogavam livremente sem qualquer tipo de intervenção do professor.

Aparentemente, o professor tinha como objetivo fazer com que aprendêssemos as práticas esportivas. No entanto, de acordo com Silva ${ }^{1}$ essa educação física fundamentalmente calcada no esporte sem trato pedagógico, permanece carente de justificação dentro do ambiente escolar.

Ainda sobre as aulas práticas, podemos descrevê-las como aquelas onde configuravam na divisão dos espaços e das atividades: homens para uma quadra e mulheres para outras Alguns alunos não participavam das aulas e ficavam sentados observando. Alguns realmente não gostavam de aulas práticas outros não participavam pela exclusão e a falta de opção já que eram disponibilizadas apenas a opção de participarem das atividades de uma das duas quadras. A quadra coberta era revezada, uma aula era dos meninos e a outra das meninas. Por vezes, acontecia a prática conjunta quando faltavam jogadores em ambas as equipes. Esta separação entre os alunos nas aulas de Educação Física não considera a articulação entre diferentes gêneros, a existência de conflitos, exclusões entre diferentes pessoas e impossibilita quaisquer formas de relação entre os meninos e as meninas ${ }^{2}$.

As aulas denominadas teóricas só eram realizadas na passagem de um esporte para o outro nas explicações das regras. O processo avaliativo era baseado nas aulas práticas onde quem participava das aulas garantia a melhor nota.Os demais conteúdos apregoados pelos autores da cultura corporal de movimento (dança, lutas, ginástica) eram deixados de lado.

Com as características descritas até o momento as aulas eram, de certa forma, atrativa apenas para quem gostava ou se identificava com os esportes. As inovações nas aulas quase não existiam. Entendemos que essas inovações seriam muito importantes para nós enquanto alunos para desenvolvermos um conhecimento mais amplo e reflexivo sobre os conteúdos da Educação Física. A problematização é uma característica da prática pedagógica inovadora que possibilita processos e experiências para a reflexão conceitua quando há o intuito de considerar a formação do pensamento crítico a partir dos conteúdos da cultura corporal. Esta postura docente promove significativas rupturas com práticas tradicionais centradas na figura do professor ${ }^{3}$.

Muitos desses professores se encontravam num processo de desinvestimento pedagógico e não tinham mais o interesse em mostrar os conteúdos da cultura corporal de movimento para aluno. Pode-se dizer que este o fenômeno denominado como prática de desinvestimento pedagógico é de caráter multifatorial. Nesse sentido, é preciso compreender que tal fenômeno 
implica, também, avaliar como se articulam os projetos de vida pessoal e profissional desses professores e o próprio ambiente de trabalho. Especificamente, no caso da Educação Física, o desinvestimento está ligado àqueles professores que ainda permanecem em seus cargos nas escolas, mas abandonaram o compromisso com a função docente ${ }^{1}$.

Alguns dos professores não buscaram outros meios de diferenciar suas práticas pedagógicas, com o passar do tempo às aulas foram se tornando rotineiras. Em outros momentos quando não queríamos praticar o que era oferecido pelo professor, as aulas eram de total liberdade e cada um fazia o que queria, sem nenhuma orientação do professor. Alguns passeavam pelo pátio da escola e acabavam atrapalhando as outras aulas e os alunos que realizavam algum

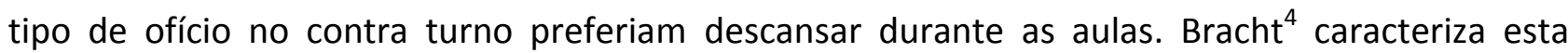
prática como não aula, onde os alunos simplesmente se divertem como fazem em momentos de recreio ou aula vaga, sem qualquer orientação pedagógica do professor.

Com todas estas problemáticas, as aulas de educação física desenvolvem sob o olhar das demais disciplinas escolares, uma característica de recreio ou aula vaga, onde o desenvolvimento dos alunos não ocorre, permanecendo em situações de atividades livres por conta da ausência do professor para orientá-lo e por professores com formação de baixa qualidade 4 .

Para nós as aulas de educação física escolar serviramcomo treinamento para as competições de jogos escolares e até mesmo jogos extraescolares. Naquele momento, nosso interesse era que o professor ensinasse o máximo de técnicas e táticas de jogo e por isso tínhamos uma ótima relação com ele. Dentro desta complexidade, o professor acabou atribuindo o esporte como principal conteúdo das suas aulas, existindo até mesmo o apoio da direção escolar para que fôssemos para jogos e colocar em destaque o nome da escola. Não é raro professores de Educação Física atribuírem ao Esporte como o conteúdo que a justifique na escola, já que, o bom professor é aquele que consegue vencer campeonatos ${ }^{1}$.

Com base nestes autores, atualmente entendemos que a Educação Física escolar tem como objeto a reflexão sobre a cultura corporal. Sob esta perspectiva, pode contribuir para a afirmação dos interesses de classe das chamadas populares, na medida em que desenvolve uma reflexão pedagógica sobre valores como solidariedade, substituindo o individualismo, cooperação confrontando a disputa, distribuição em confronto com a expropriação, sobretudo enfatizando a liberdade de expressão dos movimentos, a emancipação, negando a dominação e submissão do homem pelo homem.

Desse modo entendemos que o esporte deve estar presente sim nas aulas de EF, porém, diferentemente daquelas aulas que vivenciamos no passado enquanto alunos da educação básica. 
Partindo de toda essa problemática o objetivo desse artigo é trazer elementos teóricos que indiquem o esporte e outras atividades da cultura corporalnas aulas de educação física não priorizando a competição, mas sim com as aulas práticas proporcionando certo relaxamento e inclusão do aluno trabalhador.

\section{METODOLOGIA}

Neste estudo, utilizamos como metodologia de pesquisa aquela denominada por pesquisa bibliográfica onde há o estudo e análise de documentos de domínio científico tais como livros, periódicos e artigos científicos, com o objetivo de proporcionar aos pesquisadores o contato direto com obras que tratem do tema em questão ${ }^{5}$.

\section{DISCUSSÃO}

Daólio ao discutir a importância da educação física para o aluno trabalhador conta que, no Brasil a maioria dos estudantes do ensino médio são trabalhadores e, sendo assim, não praticam as aulas de Educação Física ${ }^{6}$.

Muitos alunos não gostam de participar das aulas e desvalorizam a disciplina. Essa prática exige um maior desgaste do professor no sentido de providenciar recursos materiais e teóricos, frente à necessidade de coordenar diferentes programações em diferentes turmas, a própria limitação de formação do professor e dificuldades em encontrar subsídios teóricos para desenvolver discussões e atividades que desenvolva o interesse nos alunos em participar das aulas que acabam adotando a prática tradicional ${ }^{7}$.

O que se propõe para as aulas de Educação Física para o aluno trabalhador é que seja oferecida uma oportunidade para uma atividade pessoal, em contrapartida ao trabalho extenuante. Uma educação física que permita ao adolescente certo relaxamento diante de determinadas atividades físicas, com a intenção de fazê-lo perceber seu corpo e capacita-lo a controlar seu corpo, em oposição ao automatismo que o trabalho muitas vezes exige. Uma educação física que permita ao aluno a prática de atividades prazerosas, em oposição à rigidez e ao caráter repressivo de muitos trabalhos. Aulas que permitam aos alunos convivência e relacionamento em grupo, já que o trabalho muitas vezes não permite estaspossibilidades, e também aulas que permitam uma aprendizagem globalizante, que aliem o cognitivo ao afetivovivencial $^{6}$.

Para tanto, é imprescindível que, para o ensino médio deva partir de um planejamento participativo, entre professores e alunos. De Ávila implementou uma proposta de atividades 
rítmicas e expressivas para alunas do curso de magistério, nível médio. Interessantemente, alunas que antes não participavam das aulas, passaram a realizá-las pelo prazer que era proporcionado. Além destes estudos, algumas escolas têm oferecido opções de práticas corporais para o ensino médio. Em uma das escolas de vanguardas da cidade de São Paulo, o aluno pode optar entre as seguintes praticas corporais, esportes coletivos, danças, jogos, e ginastica, lutas, capoeira e circo ${ }^{7}$.

Em outra escola alunos que sempre pediam dispensa das aulas de educação física por causa do trabalho, foi reduzido pela metade, quando além dos esportes, podiam optar pelas aulas de ginástica aeróbica e step, e outras atividades oferecidas até mesmo em academias. Desta forma, o esporte foi objeto de intervenção pedagógica permitindo que o seu ensino ultrapassasse situações de simples vivências para momentos que possibilitou compreensão dialética do conteúdo em si ${ }^{7}$.

Além disso, o ensino da EF tem também um sentido lúdico que busca instigar criatividade humana a adoção de uma postura produtiva e criadora de cultura, tanto no mundo do trabalho como no do lazer ${ }^{8}$.

\section{CONCLUSÕES}

Atualmente o ensino da Educação Física envolve diversos temas e elementos, para além dos esportes, que fazem parte da cultura corporal de movimento e devem ser trabalhados nas escolas, por exemplo, danças, lutas, jogos populares e o esporte. Sendo assim, as aulas de educação física podem avançar as propostas predominantemente esportistas de outrora favorecendo a participação de maior número de alunos, inclusive os alunos que não gostam de esportes e aqueles que preferem descansar durante as aulas após períodos de trabalho.

Segundo os autores citados acima aulas que os professores oferecem inovações, atividades rítmicas e expressivas para os alunos do magistério, planejamento participativo entre professores e alunos proporciona, além do desenvolvimento motor e psicológico, gera certo "relaxamento" para o aluno trabalhador em relação as outras disciplinas escolares. Estas práticas inovadoras tornam as aulas prazerosas, atrativas e a participação dos alunos nessas aulas aumentam.

\section{REFERÊNCIAS}

1.

Machado T. S., Bracht V., Faria B. de A., Moraes C., Almeida U., Almeida F. Q. As praticas de desinvestimento pedagógico na Educação Física escolar. Movimento, Porto Alegre. V. 16 , n. 02, abril-junho de 2010, p. $130-147$.

2. Souza E. S. de; Altmann H. Meninos e Meninas: Expectativas corporais e implicações na educação física escolar. Cadernos Cedes, ano XIX, n. 48, Agosto/1999, 52-68. 
3. Faria B. A., Bracht V., Machado T. S., Moraes C. A., Almeida U. R., Almeida F. Q. de. Inovações pedagógicas na educação Física: O que aprender com as praticas bem sucedidas; Ágora para La EFy el Deporte, no 12 (1) 2010, p. 11-28.

4.

Oliveira, M. M. Como fazer pesquisa qualitativa. Petrópolis: Vozes, 2007.

5. Daolio, J. A importância da educação física para o adolescente que trabalha: uma abordagem psicológica. Revista Brasileira de Ciências do Esporte, Campinas, 1986, 134-139.

6. Darido, S. C.; Galvão, Z. Ferreira, L. A.; Fiorin, G. Educação Física no ensino médio: reflexões e ações. Motriz, v. 5, n. 2, 1999, p. 138-145.

7. De Ávila, A. C. V. Para além do esporte: a expressão corporal nas aulas de Educação Física do segundo grau. Rio Claro: UNESP, Monografia de Graduação, Instituto de Biociências, Departamento de Educação Física, 1995.

8. Coletivo de autores. Metodologia do ensino de Educação Física. Editora Cortez, 2009. 